\title{
Research Productivity of Orthopaedic Sports Medicine Fellowship Programs in the United States
}

\author{
Sean C. Clark, M.S., Luke Sanborn, B.S., Symone M. Brown, M.P.H., \\ Jeffrey D. Trojan, M.S., and Mary K. Mulcahey, M.D.
}

\begin{abstract}
Purpose: To survey orthopaedic sports medicine fellowship program directors to determine the current research productivity of both fellows and faculty in Accreditation Council for Graduate Medical Education-accredited orthopaedic sports medicine fellowship programs in the United States. Methods: An anonymous 18-question survey was distributed via e-mail to all 95 Accreditation Council for Graduate Medical Education-accredited orthopaedic sports medicine fellowship program directors in the United States. Descriptive statistics were used for data analysis. Questions included whether fellows are required to complete a certain number of projects during their fellowship year and whether fellows have protected research time. Results: Of the programs, 31 (33\%) responded to the survey. Twenty-four programs $(80 \%)$ require fellows to complete 1 to 4 projects. Twenty-one programs $(71 \%)$ provide 4 to 8 hours of weekly protected research time. Twenty-four programs (77\%) publish 1 to 2 manuscripts per fellow during the fellowship. Twenty-two programs $(71 \%)$ have fellows work on 1 to 2 projects at a time. Annually, 26 programs (84\%) give 0 to 5 podium presentations, $24(80 \%)$ present 0 to 5 posters, and $15(48 \%)$ report 0 to 5 publications. Twenty-four programs $(77 \%)$ have research fellows and/or assistants to help with research. The presence of dedicated research assistants and more than 25 annual fellowship program publications were found to be useful screening data for more than 2 and more than 4 average publications per fellow, respectively. Conclusions: The research productivity of orthopaedic sports medicine fellowship programs may be an important consideration for applicants. Applicants who desire to be productive in research during their fellowship year should consider programs with dedicated research assistants and/or programs that publish more than 25 times annually. Clinical Relevance: This is a descriptive epidemiologic study that helps define the research productivity landscape in orthopaedic sports medicine fellowships. A more accurate understanding of sports medicine fellowship research experience may facilitate a better match between a program's research expectations and an applicant's research interests.
\end{abstract}

$\mathbf{F}$ ellowships are an important way to gain additional training in a specific area of interest, enhance clinical expertise, and ultimately, improve patient

From Tulane University School of Medicine, New Orleans, Louisiana, U.S.A. (S.C.C., J.D.T.); Drexel University College of Medicine, Philadelphia, Pennsylvania, U.S.A. (L.S.); and Department of Orthopaedic Surgery, Tulane University School of Medicine, New Orleans, Louisiana, U.S.A. (S.M.B., M.K.M.).

The authors report no conflicts of interest in the authorship and publication of this article. Full ICMJE author disclosure forms are available for this article online, as supplementary material.

Received July 20, 2020; accepted February 18, 2021.

Address correspondence to Mary K. Mulcahey, M.D., Department of Orthopaedic Surgery, Tulane University School of Medicine, 1430 Tulane Ave, Ste 8632, New Orleans, LA 70118, U.S.A.E-mail: mary.mulcahey.md@ gmail.com

(C) 2021 THE AUTHORS. Published by Elsevier Inc. on behalf of the Arthroscopy Association of North America. This is an open access article under the CC BY-NC-ND license (http://creativecommons.org/licenses/by-nc-nd/4.0/). 2666-061X/201223

https://doi.org/10.1016/j.asmr.2021.02.007 outcomes. Within the field of orthopaedic surgery, recent literature has shown that more than $90 \%$ of graduating orthopaedic residents go on to pursue at least 1 year of fellowship training. ${ }^{1}$ There is even an increasing trend in the percentage of orthopaedic graduates who pursue 2 fellowship programs, with a mean of $4.5 \%$ between 2004 and 2016 and $7.6 \%$ in $2014 .^{2-4}$ Orthopaedic sports medicine fellowships are among the most popular, representing 95 of the 252 Accreditation Council for Graduate Medical Education (ACGME)-accredited orthopaedic surgery fellowship programs and accounting for $40 \%$ of all orthopaedic subspecialty fellows. ${ }^{5,6}$ According to the San Francisco Match (SF Match), $86 \%$ of the total 226 sports medicine fellowship positions were filled in 2017 . $^{7}$

Given the importance of research in the advancement of orthopaedic surgery and its potential contribution to program prestige, ${ }^{8}$ the research productivity of a fellowship program may be considered and prioritized by residents applying for fellowships. This is especially 


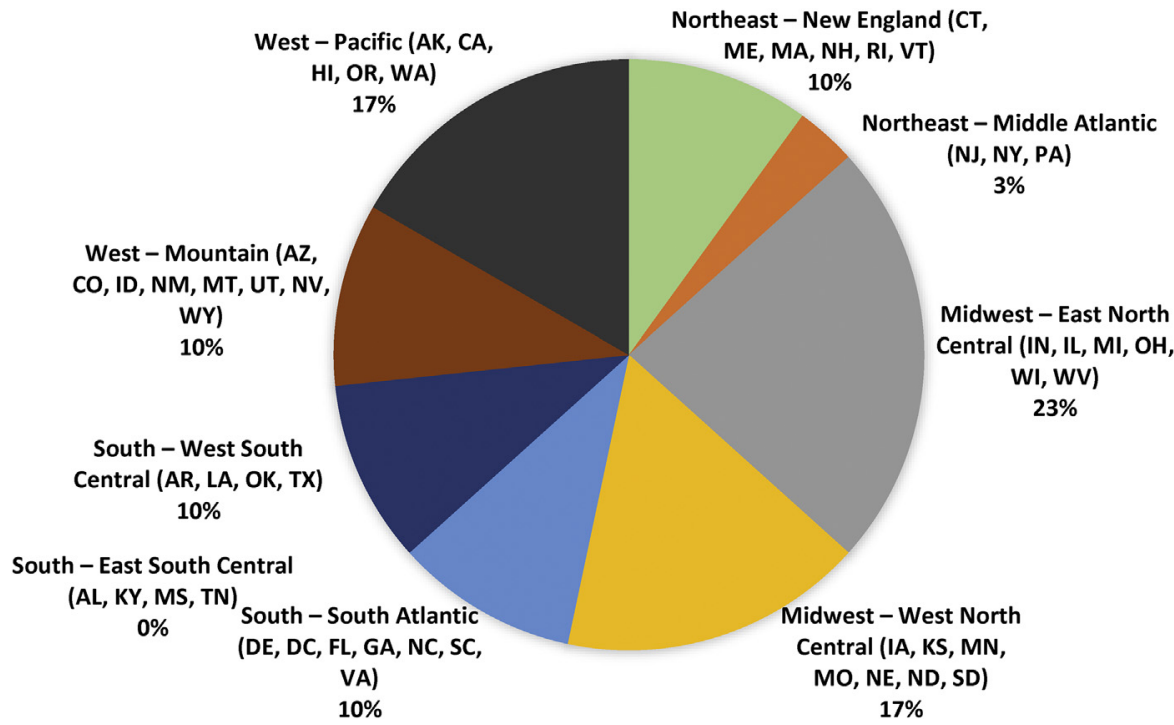

Fig 1. Geographic distribution of respondents. true for applicants seeking a career in academia because multiple studies have shown that fellowship-trained physicians have higher research productivity than non-fellowship-trained physicians. ${ }^{9-14}$

Research is considered an important component of the sports medicine fellowship year by the ACGME, given that participation in basic and/or clinical hypothesis-based research is mandatory for program accreditation. ${ }^{6}$ Programs must also schedule protected time and provide facilities for research activities. ${ }^{6}$ Sports medicine fellowship applicants rely heavily on information available on fellowship program websites to learn more about the specifics of the program, including research opportunities. ${ }^{15}$ However, data are frequently absent or overgeneralized. In 2013, Mulcahey et al. ${ }^{15}$ evaluated the websites of all ACGME-accredited orthopaedic sports medicine fellowship programs and found that only $69 \%$ of websites explained their research requirements, $32 \%$ listed conferences or meetings that were attended by their fellows, and $23 \%$ listed current or previous projects. A follow-up study by the same group in 2017 reported similar results $(61 \%, 42 \%$, and $20 \%$, respectively),

Table 1. Number of Fellows and Faculty in Orthopaedic Sports Medicine Fellowship Programs

$\%$ of Programs

\begin{tabular}{lc}
\hline No. of fellows & 37 \\
1 & 33 \\
$2-3$ & 17 \\
$4-5$ & 13 \\
$>5$ & \\
No. of faculty & 42 \\
$1-5$ & 42 \\
$6-10$ & 10 \\
$11-15$ & 6 \\
$>20$ & \\
\hline
\end{tabular}

showing a lack of improvement in addressing this issue. ${ }^{16}$ Other information, such as the amount of dedicated time available for hands-on research, is often not available online despite its strong predictive value of research productivity during the fellowship year. ${ }^{17}$ Without this information, applicants are left to speculate about levels of desired research productivity, which makes it difficult to compare and ultimately select programs that accurately embody their research interests.

The purpose of this study was to survey orthopaedic sports medicine fellowship program directors (PDs) to determine the current level of research productivity of both fellows and faculty in ACGME-accredited orthopaedic sports medicine fellowship programs in the United States. We hypothesized that programs with protected research time along with dedicated research assistants would have greater research productivity for sports medicine fellows.

\section{Methods}

Our institutional review board determined that this study did not constitute human subjects research and hence did not require institutional review board approval. An anonymous, online 18-question survey (SurveyMonkey, San Mateo, CA) was distributed via e-mail to PDs of all 95 ACGME-accredited orthopaedic sports medicine fellowships in the United States

Table 2. Required Number of Research Projects to be Completed by Fellows

\begin{tabular}{lc}
\hline $\begin{array}{c}\text { Required No. of Completed } \\
\text { Projects }\end{array}$ & $\begin{array}{c}\text { \% of Programs With } \\
\text { Requirement }\end{array}$ \\
\hline $1-2$ & 67 \\
$3-4$ & 13 \\
$>4$ & 3 \\
No requirement & 17 \\
\hline
\end{tabular}


Fig 2. Average number of publications per sports medicine fellow during fellowship year and within 2 years after fellowship from work performed during fellowship.

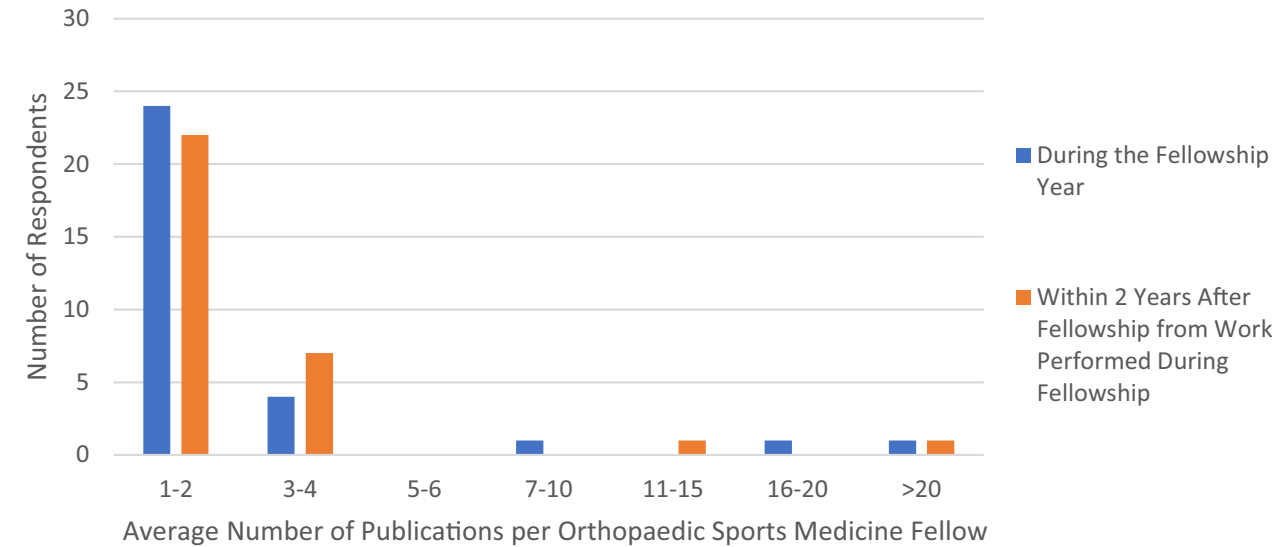

(Appendix 1). A follow-up e-mail was sent 2 and 4 weeks after initial communication to encourage more participation. Questions included whether fellows are required to complete a certain number of projects during their fellowship year, the average number of publications per fellow during the fellowship year, and whether fellows have protected research time. Descriptive statistics were used to analyze the data.

\section{Results}

\section{Respondent Program Demographic Characteristics}

Of the 95 PDs, 31 (33\%) responded, 22 of whom $(71 \%)$ were at orthopaedic sports medicine fellowship programs that are affiliated with medical schools. The 3 most-represented geographic regions were East North Central (7 programs, 23\%), West North Central (5 programs, 17\%), and Pacific (5 programs, 17\%) (Fig 1). Of the programs, $11(37 \%)$ had 1 fellow, $10(33 \%)$ had 2 to 3 fellows, 5 (17\%) had 4 to 5 fellows, and $4(13 \%)$ had more than 5 fellows. Moreover, 13 fellowship programs $(42 \%)$ reported having 1 to 5 faculty members, $13(42 \%)$ had 6 to $10,3(10 \%)$ had 11 to 15 , and 2 $(6 \%)$ had more than 20 (Table 1). The average faculty member's academic career length, defined as the number of years since his or her first publication, was variable, with most responses being 11 to 15 years $(29 \%)$ or 16 to 20 years $(23 \%)$.

\section{Program Research Expectations and Support}

Twenty programs $(67 \%)$ require fellows to complete 1 to 2 projects per year, $4(13 \%)$ require 3 to 4 projects, and $1(3 \%)$ requires 12 projects (Table 2$)$. The remaining 5 programs $(17 \%)$ do not require a set number of projects. Additionally, 25 programs ( $83 \%$ ) have protected research time, with 21 programs $(70 \%)$ providing from 4 hours per week (10 programs, $33 \%)$ to 8 hours per week (11 programs, $37 \%)$. Fifteen programs $(50 \%)$ offer basic science, clinical, and biomechanical research opportunities, whereas $12(40 \%)$ offer only clinical research. Twenty-four programs $(77 \%)$ provided research fellows or assistants to help with conducting research.

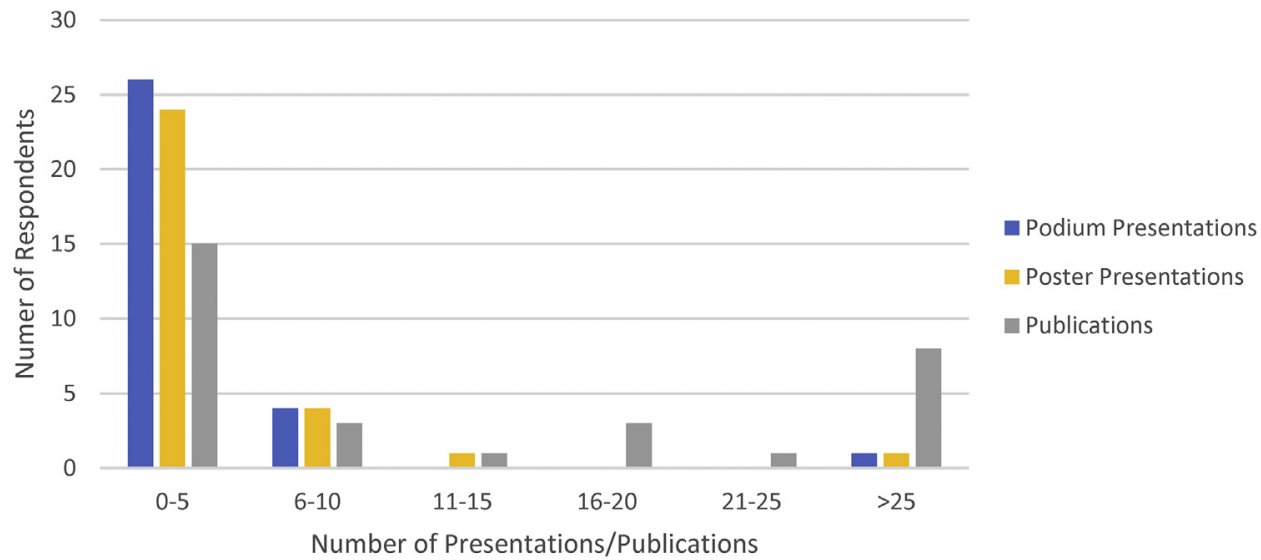

Fig 3. Annual research productivity of orthopaedic sports medicine fellowship programs. 


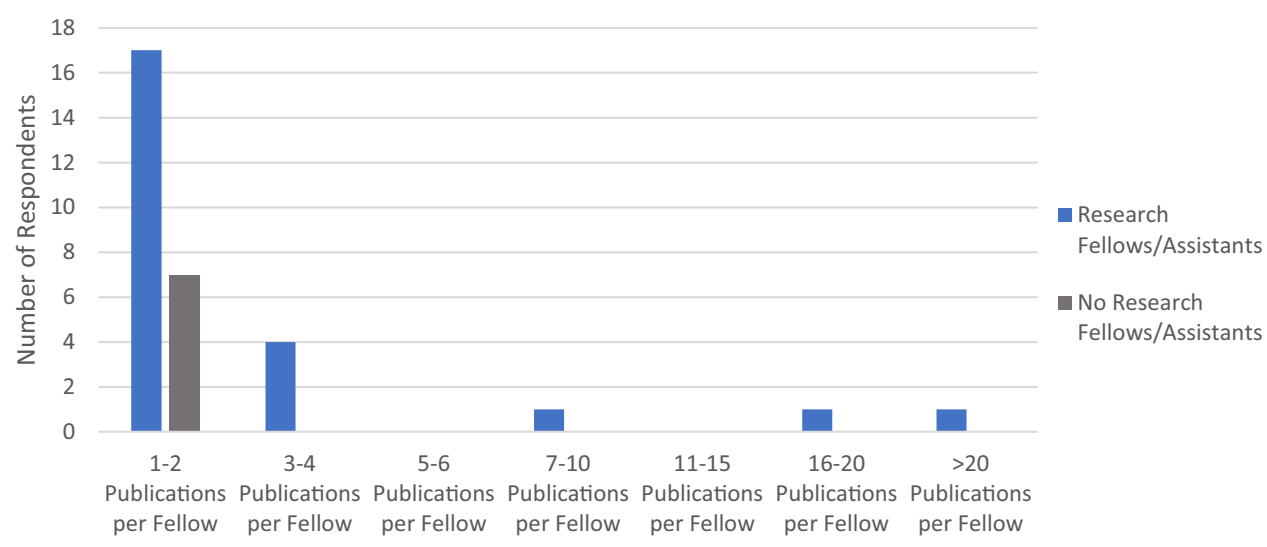

Fig 4. Association of available research fellows and/or assistants and publications per fellow.

\section{Research Productivity of Sports Medicine Fellows}

In 24 programs (77\%), fellows average 1 to 2 publications per year, with fellows in the other 7 programs $(23 \%)$ ranging from 3 to more than 20 publications (Fig 2). Twenty-two programs (71\%) average 1 to 2 publications per fellow in the 2 years after the fellowship as a result of work that was performed during the fellowship, 7 programs $(23 \%)$ average 3 to 4 publications per fellow, 1 program $(3 \%)$ averages 11 to 15 publications per fellow, and 1 program $(3 \%)$ averages $>20$ publications per fellow in the subsequent 2 years (Fig 2). At any given time, fellows work on 1 to 2 projects ( 22 programs, $71 \%$ ), 3 to 4 projects ( 5 programs, $16 \%$ ), 5 to 6 projects ( 3 programs, $10 \%$ ), or more than 8 projects ( 1 program, $3 \%$ ). Additionally, 22 programs $(71 \%)$ have each fellow attend 2 to 3 conferences per year, with 8 programs $(26 \%)$ sending fellows to 4 or more conferences.

\section{Research Productivity of Sports Medicine Fellowship Programs}

The average number of publications among all sports medicine fellowship faculty in the past 5 years varied considerably, with 11 programs (35\%) publishing 0 to 5 articles, $7(23 \%)$ publishing 6 to $10,4(13 \%)$ publishing 11 to $15,3(10 \%)$ publishing 16 to $20,1(3 \%)$ publishing 21 to 25 , and 5 ( $16 \%$ ) publishing more than 25. Fellows combined to give a total of 0 to 5 podium presentations annually in 26 programs $(84 \%), 6$ to 10 presentations in 4 programs $(13 \%)$, and over 10 presentations in 1 program $(3 \%)$. Additionally, fellows combined to present 0 to 5 poster presentations in $80 \%$ of programs. Fifteen programs $(48 \%)$ averaged 0 to 5 total program publications per year (faculty and fellows combined) and 8 programs $(26 \%)$ averaged over 25 , with the remaining programs somewhere between these numbers (Fig 3). Twenty-two programs (71\%) reported that $0 \%$ to $25 \%$ of fellows pursue careers in academic positions after their fellowships.

\section{Discussion}

This study showed that most orthopaedic sports medicine fellowship programs in the United States require 1 to 4 projects to be completed during the fellowship year, provide from 4 to 8 hours of protected research time per week, and publish an average of 1 to 4 manuscripts per fellow during the fellowship year. The total number of publications per fellowship program varied considerably. However, total program podium presentations and poster presentations were found to be more consistent, with 26
Fig 5. Association of total annual orthopaedic sports medicine fellowship program publications and number of publications per fellow.

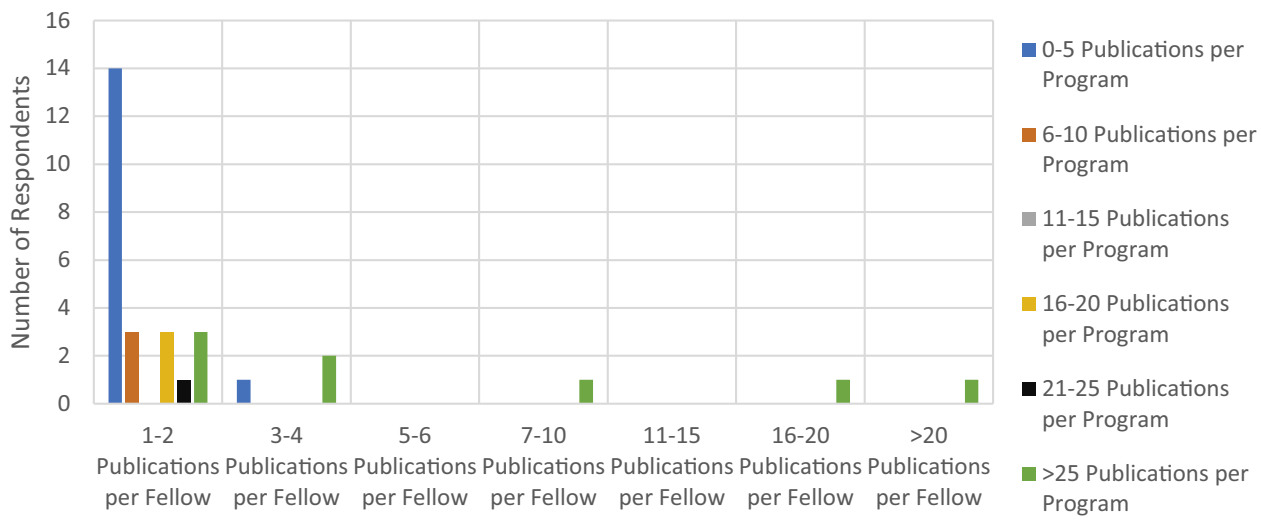


programs (84\%) and 24 programs $(80 \%)$ reporting 5 or fewer podium presentations and 5 or fewer poster presentations, respectively (Fig 3). The number of conferences attended annually by sports medicine fellows was relatively consistent as well, with 22 programs $(71 \%)$ reporting sending fellows to 2 to 3 conferences per year.

Two data sets were found to be valuable screening data for research productivity per fellow: average number of publications by the entire program and presence of research fellows or research assistants to help with conducting research. If a sports fellowship applicant desires to publish more than 2 projects during the fellowship year, our data suggest that he or she should seek programs with dedicated research assistants because no programs in our study without such assistants were found to have an average annual fellow publishing rate above 2 (Fig 4). If an applicant wishes to publish more than 4 projects during the fellowship year, our data suggest that he or she should seek programs with greater than 25 total annual publications per year (Fig 5). There are currently limited data regarding the average productivity per orthopaedic sports medicine fellow for comparison.

A 2016 study by Cvetanovich et al. ${ }^{8}$ evaluated the total number of publications by 610 sports medicine faculty across 90 orthopaedic sports medicine fellowship programs in the United States. They found that faculty members had a median of 18 total publications (range, 0-684 publications), with a median of 3 publications (range, 0-161 publications) in the preceding 5 years. They also found that programs with more fellows tended to have faculty with a higher Hirsch index, a metric of research productivity and citation impact. It is interesting to note that the Midwest and Northeast regions were found to have higher average faculty research productivity than the Southern and Western regions, showing a need to consider geographic trends in program assessment. ${ }^{8}$ The existing data are helpful; however, they are limited to the research productivity of individual faculty members, rather than programs as a whole.

Previous studies have shown the importance of research productivity in the process of ranking orthopaedic sports medicine fellowship programs. ${ }^{15,16}$ To improve the accuracy of rankings based on this criterion, it would be helpful for applicants to know the quantitative nationwide distribution of research productivity for comparison against specific programs. This study offers the first metrics of fellow-specific and program-specific sports medicine fellowship research productivity and contributes to the existing body of literature regarding faculty research productivity within sports fellowship programs. Other studies within medicine have also shown the importance of research when evaluating and ranking fellowship programs. For example, Caiola and Litaker ${ }^{18}$ retrospectively surveyed 149 general medicine fellows across 30 programs and reported that research opportunities were the second-most important selection factor influencing the selection of their fellowship programs. However, our review of the literature failed to find any quantitative reports of general medicine research productivity for comparison.

\section{Limitations}

There are several limitations to this study. First, given the relatively low response rate of $33 \%$, our results may not be generalizable to all sports medicine fellowship programs in the United States. Second, some survey questions may have been interpreted differently or incorrectly. Third, many of our survey response ranges included 0 (e.g., 0-5), thereby making it impossible to determine whether the response was 0 or between 1 and the upper end of the range listed. Finally, this was a survey-based study and hence is subject to the inherent limitations of such a study design including recall bias. Many of the questions required PDs to provide an estimate based on memory. The accuracy of these data could be improved by searching for publications by all faculty and fellows; however, this information is not readily available for all sports medicine fellowship programs.

\section{Conclusions}

The research productivity of orthopaedic sports medicine fellowship programs may be an important consideration for applicants. Applicants who desire to be productive in research during their fellowship year should consider programs with dedicated research assistants and/or programs that publish more than 25 times annually.

\section{References}

1. Horst PK, Choo K, Bharucha N, Vail TP. Graduates of orthopaedic residency training are increasingly subspecialized: A review of the American Board of Orthopaedic Surgery part II database. J Bone Joint Surg Am 2015;97:869-875.

2. Daniels A, DiGiovanni C. Is subspecialty fellowship training emerging as a necessary component of contemporary orthopaedic surgery education? J Grad Med Educ 2014;6:218-221.

3. Hariri S, York S, O'Connor M, Parsley B, McCarthy J. Career plans of current orthopaedic residents with a focus on sex-based and generational differences. J Bone Joint Surg Am 2011;93:e16.

4. DePasse JM, Daniels AH, Durand W, Kingrey B, Prodromo J, Mulcahey MK. Completion of multiple fellowships by orthopedic surgeons: Analysis of the American Board of Orthopaedic Surgery certification database. Orthopedics 2018;41:e33-e37.

5. Daniels AH, Grabel Z, DiGiovanni CW. ACGME accreditation of orthopaedic surgery subspecialty fellowship training programs. J Bone Joint Surg Am 2014;96:e94.

6. Accreditation Council for Graduate Medical Education. wwwacgmeorg. Published 2017. Accessed April 20, 2018.

7. sfmatch. Orthopaedics fellowship: sports medicine, https:// www.sfmatch.org/SpecialtyInsideAll.aspx?id=32\&typ $=1$ \& 
name $=$ Sports $\% 20$ Medicine $\delta$ mainSpecialty $=$ Orthopaedics \%208subspec=28\#. Accessed December 20, 2020.

8. Cvetanovich GL, Saltzman BM, Chalmers PN, Frank RM, Cole BJ, Bach BR Jr. Research productivity of sports medicine fellowship faculty. Orthop J Sports Med 2016;4: 2325967116679393.

9. Huang G, Fang CH, Lopez SA, Bhagat N, Langer PD, Eloy JA. Impact of fellowship training on research productivity in academic ophthalmology. J Surg Educ 2015;72:410-417.

10. John AM, Gupta AB, John ES, Lopez SA, Lee B, Lambert WC. The impact of fellowship training on scholarly productivity in academic dermatology. Cutis 2016;97:353.

11. Sood A, Therattil PJ, Chung S, Lee ES. Impact of subspecialty fellowship training on research productivity among academic plastic surgery faculty in the United States. Eplasty 2015;15:e50.

12. Akl EA, Meerpohl JJ, Raad D, et al. Effects of assessing the productivity of faculty in academic medical centres: A systematic review. CMAJ 2012;184:E602-E612.
13. Salter SA, Kimball AB. Rising educational debt levels in recent dermatology trainees and effects on career choices. J Am Acad Dermatol 2006;54:329-331.

14. Tierney EP, Hanke WC, Kimball AB. Recent changes in the workforce and practice of dermatologic surgery. Dermatol Surg 2009;35:413-419.

15. Mulcahey MK, Gosselin MM, Fadale PD. Evaluation of the content and accessibility of web sites for accredited orthopaedic sports medicine fellowships. J Bone Joint Surg Am 2013;95:e85.

16. Yayac M, Javandal M, Mulcahey MK. Accredited orthopaedic sports medicine fellowship websites: An updated assessment of accessibility and content. Orthop J Sports Med 2017; 5:2325967116683942.

17. Steiner JF, Lanphear BP, Curtis P, Vu KO. Indicators of early research productivity among primary care fellows. J Gen Intern Med 2002;17:854-860.

18. Caiola E, Litaker D. Factors influencing the selection of general internal medicine fellowship programs: A national survey. J Gen Intern Med 2000;15:656-658. 